\title{
Efficacy of Platelet-Rich Plasma versus Hyaluronic Acid for treatment of Knee Osteoarthritis: A systematic review and meta-analysis
}

Hassan Niroomand Sadabad ${ }^{1}$, Masoud Behzadifar ${ }^{2}$, Farzad Arasteh $^{3}$, Meysam Behzadifar ${ }^{4}$, Hamid Reza Dehghan $^{5}$

${ }^{1}$ M.Sc. of Health Technology Assessment (HTA), Department of Health Technology Assessment, Faculty of Health, Shahid Sadoughi University of Medical Sciences, Yazd, Iran

${ }^{2} \mathrm{Ph} . D$. Student of Health Policy, Health Management and Economics Research Center, Iran University of Medical Sciences, Tehran, Iran

${ }^{3}$ M.D. of Orthopedics, Assistant Professor, Department of Orthopedic, Faculty of Medicine, Islamic Azad University, Mashhad, Iran

${ }^{4}$ M.Sc. Of Epidemiology, Department of Public Health, Faculty of Health and Nutrition, Lorestan University of Medical Sciences, Khorramabd, Iran

${ }^{5}$ M.D, Department of Health Technology Assessment, Faculty of Health, Shahid Sadoughi University of Medical Sciences, Yazd, Iran

Type of article: Meta-analysis

\begin{abstract}
Introduction: Knee osteoarthritis is a very common chronic degenerative disease that could impose significant costs to the health system. Although osteoarthritis can affect all joints, knee osteoarthritis is the most common type among adolescents. Non-surgical treatments include corticosteroids injection, hyaluronic acid, and plateletrich plasma. The aim of this study was to investigate the efficiency of platelet-rich plasma versus hyaluronic acid for the treatment of knee osteoarthritis.

Methods: Pubmed, Cochran library, Scopus and Ovid databases were investigated to identify related studies from 2000 through August 2015. To study the efficiency, Western Ontario and McMaster Universities Osteoarthritis Index (WOMAC) outcome using the Standard Mean Difference (SMD) index was calculated using a random model and a confidence interval of $95 \%$. In addition, sensitivity and cumulative analysis were conducted. The data were analyzed using RevMan 5.3.5 and Stata 12 software.

Results: Seven studies with 722 subjects (364 participants in PRP and 358 participants in the HA group) were analyzed. The WOMAC PRP compared to HA, SMD $=-0.75(95 \%$ CI: -1.33 to $-0.18, \mathrm{I} 2=92.6 \%)$ in treatment of knee osteoarthritis was statistically significant and PRP was more effective.

Conclusion: The results of this meta-analysis two years after PRP injection showed the efficacy of PRP versus HA. However, further studies are required to determine the longer-term effects.

Keywords: platelet-rich plasma; hyaluronic acid; efficacy, meta-analysis
\end{abstract}

\section{Introduction}

Knee osteoarthritis is a very common chronic degenerative disease that can impose significant costs to the health system (1). In osteoarthritis, first gnawing of articular cartilage and engagement of the bones under the cartilage occur, resulting in inflammation of the surrounding tissues. This complication may engage any joint, and destruction of cartilage is the hallmark sign of the disease (2-4). This disease is known as one of top 10 causes of disability all across the world (5). Although arthritis can affect all joints, knee osteoarthritis is the most common type among adolescents. According to the results of some studies, the prevalence of knee osteoarthritis varies from 6 to $40 \%$, and

\section{Corresponding author:}

Hamid Reza Dehghan. Department of Health Technology Assessment, Faculty of Health, Shahid Sadoughi University of Medical Sciences, Yazd, Iran.

Tel: +98.5138072550, Fax: +98.5138818300, Email: hamidreza.dehghan@gmail.com

Received: December 22, 2015, Accepted: February 12, 2016, Published: March 2016

iThenticate screening: February 11, 2016, English editing: February 26, 2016, Quality control: March 04, 2016

(C) 2016 The Authors. This is an open access article under the terms of the Creative Commons Attribution-NonCommercialNoDerivs License, which permits use and distribution in any medium, provided the original work is properly cited, the use is non-commercial and no modifications or adaptations are made. 
it increases with age (6). Knee osteoarthritis is more common in females than in males (7). The most common symptoms of knee osteoarthritis are pain and physical limitations that have a significant effect on the individual's quality of life and her or his social and economic activities $(6,8)$. Due to the increase in life expectancy, the number of elderly people, and the prevalence of obesity in society, it seems that the prevalence of knee osteoarthritis will increase. This will be one of the serious problems of health system that imposes great costs to societies. Today, drug therapies, including painkillers, corticosteroids, glucosamine, chondroitin, sulfate, and non-steroid antiinflammatory drugs are used along with viscosupplementation to relieve pain and symptoms as well as to slow the progression of the arthritis (6). In addition, intra-articular injection is used as a good option for drug therapy of arthritis (9). Hyaluronic acid (HA) and platelet-rich plasma (PRP) are two treatment options that are used (10, 11). Studies that have used these two methods separately to treat knee osteoarthritis have verified their efficiency in reducing pain and improving joint function. In addition, mild side effects were observed in these studies. Pain, inflation, and mild limitations in join function are observed after injection $(12,13)$. The aim of this study was to investigate the effectiveness of intra-articular injection of platelet-rich plasma compared to hyaluronic acid for the treatment of osteoarthritis of the knee.

\section{Material and Methods}

\subsection{Research Design}

This was a systematic review and meta-analysis study conducted to investigate the effectiveness of platelet-rich plasma versus hyaluronic acid for treatment of knee osteoarthritis in 2015.

\subsection{Study Search}

To identify related studies, Pubmed, Cochran library, Scopus, and Void databases were investigated from 2005 through August 2015. Keywords were used based on Medical Subject Headings (MeSH) for searching. The sarching strategy included "Platelet-Rich Plasma "OR "PRP” OR "Platelet" AND "Hyaluronic Acid" OR "HA" AND "Knee Osteoarthritis. In addition, orthopedic and rheumatology conferences related to knee osteoarthritis were considered, including the European Federation of National Association of Orthopedics and Traumatology (EFFORT), American Academy of Orthopedic Surgeons (AAOS), American College of Rheumatology, and the European League Against Rheumatism (EULAR). Also, a reference list of identified articles and theses was investigated to find more studies. In searching for related studies, language barriers were not considered. The results of the searches were reported based on Preferred Reporting Items for Systematic Reviews and Meta-Analyses (PRISMA) guide (14).

\subsection{Inclusion and Exclusion Criteria}

Inclusion criteria for this study were 1) randomized clinical trials in which knee osteoarthritis was identified and 2) studies in which platelet-rich plasma and hyaluronic acid were utilized. The exclusion criteria for this study were 1) studies with unknown results and methodology and 2) studies conducted on patients with knee osteoarthritis who had other diseases as well.

\subsection{Outcome Measures}

The main important outcome of the efficacy and response to treatment for recovery used in this systematic review was the WOMAC score (15).

\subsection{Data Extraction}

Based on the inclusion and exclusion criteria of the study, two explorers independently investigated the titles and abstracts of studies. Then, studies were selected to be included in the meta-analysis. When there were differences between the two explorers, a third party acted as a referee, and the dispute was resolved by discussion. The variables that were extracted from the studied included the name of the corresponding author, publication date, country in which the study was conducted, age of the people, sample size, and the WOMAC score. Then, the data were entered into a Microsoft Excel database (Version 2010, Microsoft Corp., Redmond, WA, USA).

\subsection{Quality Assessment}

To assess the quality of the studies, we used the Cochrane Collaboration "Risk of bias" (16). In addition, the Jadad scale was used to assess the quality of the randomized clinical trials (RCTs) studies, (17). This scale included randomization, blinding, and dropout items. In this standard, the scores ranged from 1 to 5 and scoring was based on the methodology. 


\subsection{Statistical Analysis}

To calculate efficiency, the Standardized Mean Differences (SMD) index was used. Data were reported based on a random model with a confidence interval of $95 \%$. Values of $p<0.05$ were regarded as statistically significant. The $\mathrm{I}^{2}$ and Q-test were used to assess the heterogeneity between the studies. In addition, to discover more heterogeneity, meta-regression was conducted on the sources of the factors for the variables of year of publication and sample size based on our previous knowledge that they could be effective factors. A funnel plot was used to assess publication bias. Considering that the number of studies should not be less than 10 to assess publication bias, publication bias was not conducted. Sensitivity analysis was conducted to verify the robustness of the results. This was done to demonstrate the effect of each study on the ultimate result. For this purpose, one of the studies was excluded and sensitivity analysis was conducted in its absence. Data from the study were entered into Stata 12.0 software (StataCorp LP, College Station, TX) and RevMan 5.3.5 software (Copenhagen, The Nordic Cochrane Center, The Cochrane Collaboration, 2015) for analysis.

\section{Results}

\subsection{Features of Included Studies}

In the primary search, 192 articles were qualified; 94 studies were iterated. The titles of 98 articles were investigated, and 56 studies were not related to this topic and were excluded. The full texts of 23 studies were investigated, and six studies were selected for the meta-analysis (18-23). Figure 1 shows the stages of searching and selecting studies for the meta-analysis. The number of participants included in the studies was 722 subjects (364 participants in PRP group and 358 participants in HA group). The average number of subjects for each study was 120. The studies that were included had been conducted from 2008 through 2015. The features of the six studies that were included are shown in Table 1.

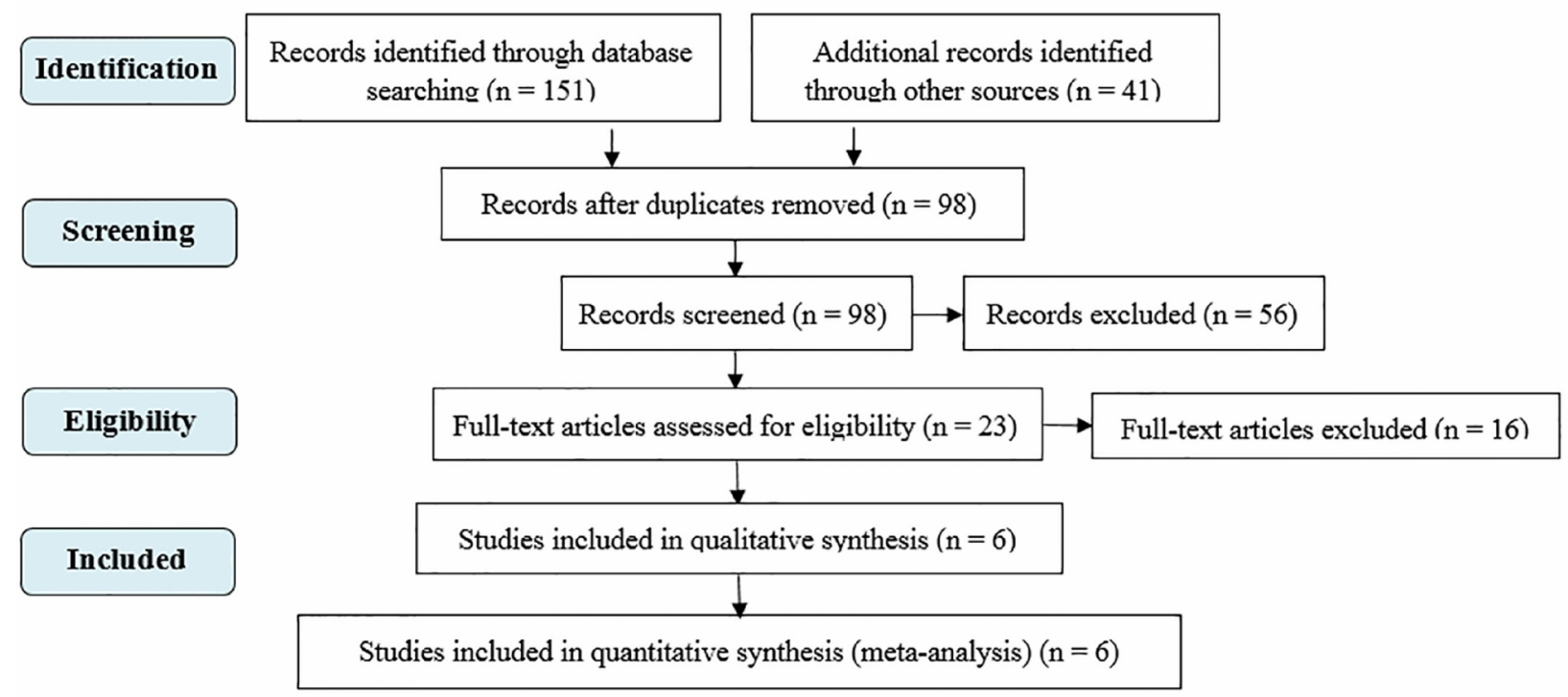

Figure 1. Flowchart of selection of included studies

Table 1. Characteristics of the studies that were included

\begin{tabular}{|l|l|l|l|l|l|l|}
\hline Author & Year & Country & Sample size & Duration (week) & Age (SD) \\
\cline { 6 - 8 } & & & & & PRP & HA \\
\hline Sanchez & 2008 & Spain & 60 & 5 & $63.53 \pm 8.91$ & $60.90 \pm 8.63$ \\
\hline Cerza & 2012 & Italy & 120 & 24 & $66.5 \pm 11.3$ & $66.2 \pm 10.6$ \\
\hline Raeissadat & 2015 & Iran & 150 & 48 & $56.85 \pm 9.13$ & $61.13 \pm 7.48$ \\
\hline Sanchez & 2012 & Spain & 176 & 24 & $60.5 \pm 7.9$ & $58.9 \pm 8.2$ \\
\hline Spakova & 2012 & Slovakia & 120 & 24 & $52.8 \pm 12.43$ & $53.2 \pm 14.53$ \\
\hline vaquerizo & 2013 & Spain & 96 & 48 & $62.2 \pm 6.6$ & $64.8 \pm 7.7$ \\
\hline
\end{tabular}




\subsection{Quality Assessment of Studies Included in the Meta-Analysis}

The studies included in the meta-analysis were assessed in terms of quality by considering Cochrane collaboration risk of bias. Figure 2 shows the results of the quality assessment. The Jadad scale was used to investigate the randomized clinical trials that were included. According to this scale, one study scored 3, three studies scored 4, and two studies scored 5. Considering the scores that were obtained, the six studies that we included were of good quality. Table 2 shows the scores of the studies that were included based on the Jadad scale.

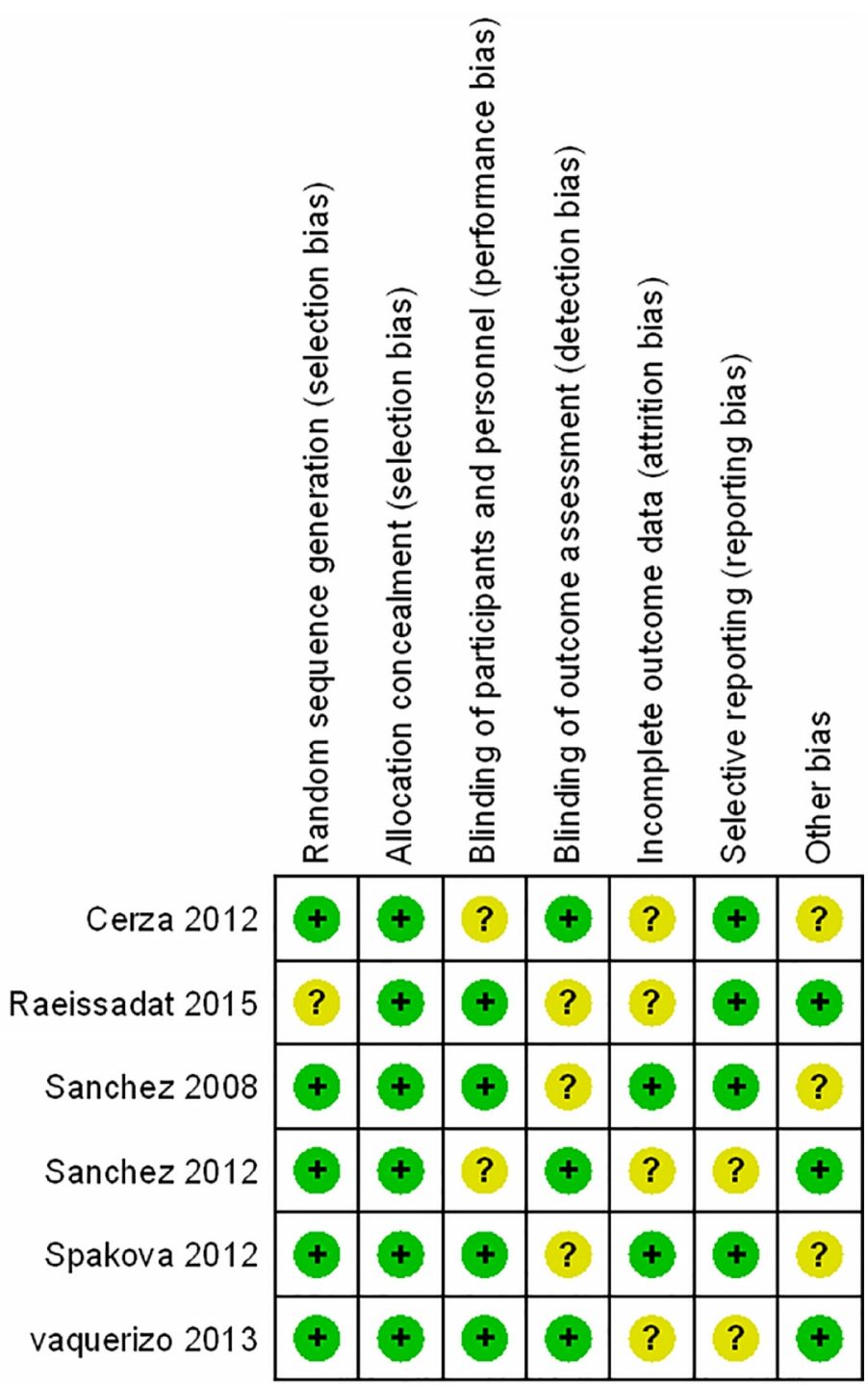

Figure 2. Risk of bias graph of the included studies

Table 2. Jadad score quality assessment of the included studies

\begin{tabular}{|l|l|l|l|l|l|}
\hline Author & Year & Randomization & Blindness & Dropouts & Jaded scores \\
\hline Sanchez & 2008 & 2 & 1 & 0 & 3 \\
\hline Cerza & 2012 & 2 & 1 & 1 & 4 \\
\hline Raeissadat & 2015 & 2 & 1 & 1 & 4 \\
\hline Sanchez & 2012 & 2 & 2 & 1 & 5 \\
\hline Spakova & 2012 & 2 & 1 & 1 & 4 \\
\hline Vaquerizo & 2013 & 2 & 2 & 1 & 5 \\
\hline
\end{tabular}




\subsection{Effectiveness of Platelet-Rich Plasma Compared to Hyaluronic Acid}

To investigate the effectiveness of the PRP and HA methods and compare them, data related to the WOMAC outcome were analyzed where SMD $=-0.75 \%(95 \% \mathrm{CI}=-1.33$ to -0.18$)$; this difference was significant because we did not include the zero effect in this confidence interval and $p=0.000$, and PRP was proved to be more effective. Figure 3 shows the general results of the comparison of the effectiveness of the PRP and HA methods.

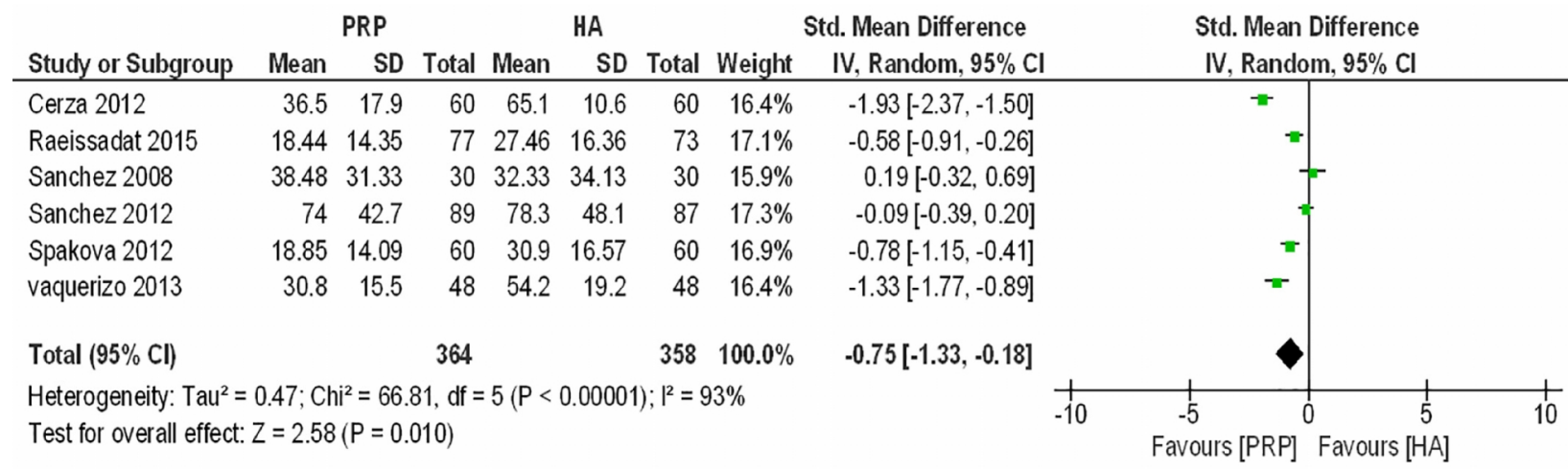

Figure 3. Forest plot of Standardized Mean Differences (SMD) and 95\% confidence intervals (CIs) of Western Ontario and McMaster University Arthritis Index (WOMAC), Platelet - Rich Plasma Compared to Hyaluronic Acid in the included studies

\subsection{Sensitivity Analysis}

Sensitivity analysis was conducted to investigate and verify the robustness of the results. For this purpose, we excluded Cerza's study because the results (SMD $=-1.94$ ) were more distant from the other studies. Then, the results were analyzed for WOMAC outcome, and $\mathrm{SMD}=-0.52 \%(95 \% \mathrm{CI}=-0.98$ to -0.06$)$ was observed. Considering this analysis, the SMD increased. Figure 4 shows the sensitivity analysis for this meta-analysis.

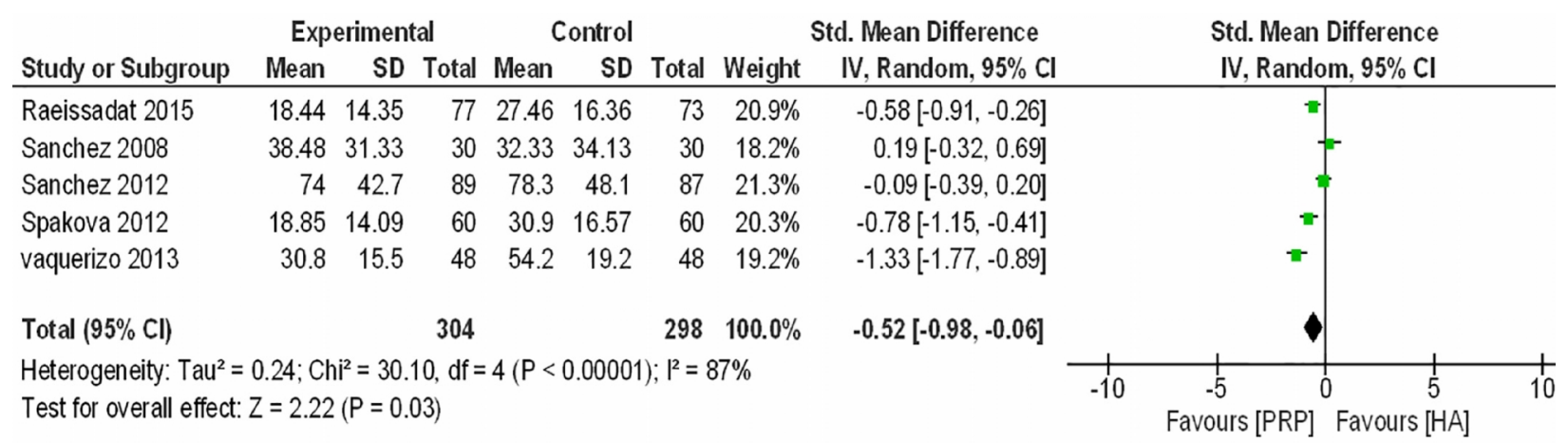

Figure 4. Sensitivity analysis of studies included

\subsection{Cumulative Meta-analysis}

In routine meta-analysis studies, attempts are made to combine the information from various studies in one step and determine their outcome. In routine meta-analysis, the order of the studies does not matter, and their final composition is the same for any order. However, in cumulative meta-analysis, the order of studies is important, and the year of publication commonly is used to arrange information. First, data related to previous studies are considered as the base, and, then, data related to later studies are added. Data related to more recent studies are added to the previous data in this way. Naturally, by adding more recent studies, the accuracy of the meta-analysis increases gradually, and, therefore, the calculated confidence range becomes smaller and smaller. Adding the results of one study in the primary stages of estimation can displace the point estimation significantly, since, compared to limited previous studies, the weight of the new study is significant. However, in later stages, the estimates that are obtained by combining the data related to more studies that have significant weight, and adding recent studies would barely affect the displacement of the point estimation significantly. To conduct cumulative meta-analysis, we first ranked studies based on the year of publication. Then, the meta-analysis was conducted, and SMD did not change. The results showed that PRP was more effective than HA. Figure 5 shows the cumulative meta-analysis. 


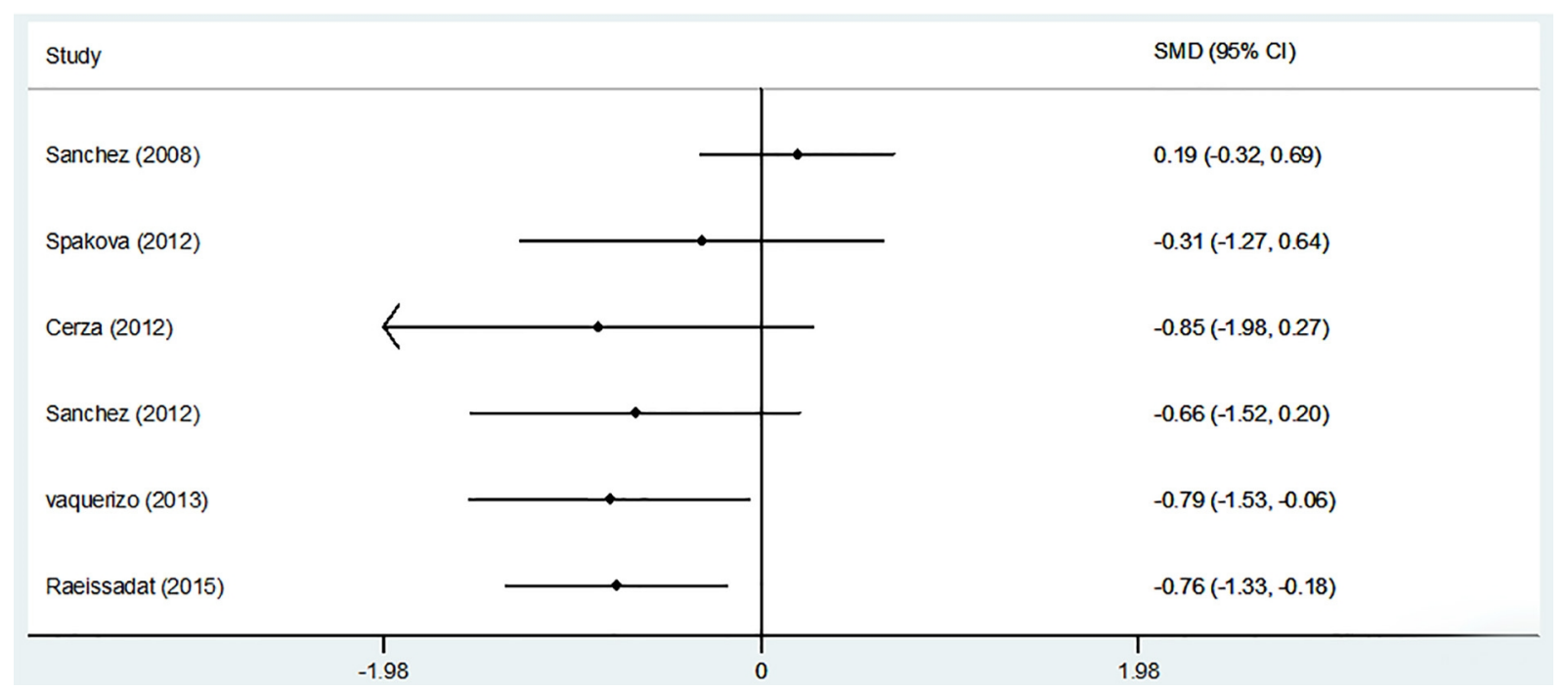

Figure 5. Cumulative analysis of studies included

\section{Discussion}

The findings of this systematic review and meta-analysis are related to efficacy of platelet-rich plasma compared to hyaluronic acid in the treatment of osteoarthritis of the knee, and the WOMAC index was evaluated. Considering the results of this study, compared to hyaluronic acid, the use of platelet-rich plasma is more effective for treatment of knee osteoarthritis (SMD = -0.75). The results of a study conducted by Khoshbin et al. (2013) (24) showed that platelet-rich plasma is a better method than hyaluronic acid. Furthermore, in another study conducted by Meheux et al. (2015) (25), the results showed that PRP was a better method for the treatment of knee osteoarthritis than HA or placebo. The results of this study were in agreement with the results of the other studies mentioned above. In a study by Chang et al. (2013) conducted using systematic review, 16 studies were investigated, and their results showed that PRP was more effective than placebo or corticosteroids (26). In some studies, for non-surgical treatment of knee osteoarthritis PRP and HA were used. In addition, there are not many studies that have compared the two methods. In studies that have used the PRP method, symptoms such as pain management and improvement of quality of life have been observed in patients (27). PRP injection for patients has shown that PRP has a greater effectiveness than HA for pain management and articular function (28). Three groups of patients were injected with PRP or HA, and, at the 6-month follow-up, the results showed that the younger patients had better articular function. When patients with knee osteoarthritis receive PRP injection, their white blood cell count increases, and they usually suffer from increased inflammation of the neutrophil muscles (29). In a study by Filardo et al. on the effect of PRP and HA on white blood cells, the results showed no statistically significant difference (30). In some other studies, no effect was observed on the effect of PRP on the number of leukocytes compared to HA or placebo. This study had some limitations, some of which were as follows: the studies included in the meta-analysis were conducted in different levels of randomized clinical trials; for example, levels 1 and 2, which could create bias in selection. High heterogeneity was observed (96.6\%), which could have been the result of then different methodologies that were used in the studies. Our sample size was small, and, for more accurate results, more studies should be conducted with larger sample sizes. This small sample size could affect the effectiveness threshold (31). The quality of the studies used in the meta-analysis also could have affected the results that were obtained. Some studies were of low quality with regard to quality assessment of articles, which, although not excluded from the analysis, could affect the results. The data in the studies we used restricted the possibility of conducting an effectiveness analysis with respect to gender. Only a few studies were included for the meta-analysis, and this did not provide the possibility to conduct regression and publication bias assessments. Follow-up was conducted for a maximum of one year, so any long-term effects are unknown.

\section{Conclusions}

The results of this review showed that PRP was more effective than HA. PRP and HA are considered as nonsurgical treatments for knee osteoarthritis. Using any of these methods has its own effects and complications. More studies should be conducted in the future to judge the efficacy of the two methods for more than a year. 


\section{Acknowledgments:}

This study is part of a Master's thesis of Health Technology Assessment (HTA) that the first author conducted with the support of the Health Technology Assessment Department at Shahid Sadoughi University of Medical Sciences in Yazd. We appreciate all of the people who assisted us in conducting this study.

\section{Conflict of Interest:}

There is no conflict of interest to be declared.

Authors' contributions:

All authors contributed to this project and article equally. All authors read and approved the final manuscript.

\section{References}

1) Wong LY, Yiu RL, Chiu CK, Lee WK, Lee YL, Kwong PK, et al. Prevalence of Psychiatric Morbidity in Chinese Subjects with Knee Osteoarthritis in a Hong Kong Orthopaedic Clinic. East Asian Arch Psychiatry 2015; 25: 150-8.

2) Berenbaum F. Osteoarthritis as an inflammatory disease (osteoarthritis is not osteoarthrosis!). Osteoarthritis Cartilage 2013; 21: 16-21. doi: 10.1016/j.joca.2012.11.012, PMid: 23194896

3) Loeser RF, Goldring SR, Scanzello CR, Goldring MB. Osteoarthritis: a disease of the joint as an organ. Arthritis Rheum 2012; 64: 1697-707. doi: 10.1002/art.34453, PMid:22392533, PMCid: PMC3366018

4) Scanzello CR, Goldring SR. The role of synovitis in osteoarthritis pathogenesis. Bone 2012; 51: 249-57. doi: 10.1016/j.bone.2012.02.012, PMid: 22387238, PMCid: PMC3372675

5) Neogi T. The epidemiology and impact of pain in osteoarthritis. Osteoarthritis Cartilage 2013; 21: 1145-53. doi: 10.1016/j.joca.2013.03.018, PMid: 23973124, PMCid: PMC3753584

6) Michael JW, Schlüter-Brust KU, Eysel P. The epidemiology, etiology, diagnosis and treat $\neg$ ment of osteoarthritis of the knee. Dtsch Arztebl Int 2010; 107: 152-62. PMid: 20305774, PMCid: PMC2841860

7) Zhang Y, Xu L, Nevitt MC, Aliabadi P, Yu W, Qin M, et al. Comparison of the prevalence of knee osteoarthritis between the elderly Chinese population in Beijing and whites in the United States: The Beijing Osteoarthritis Study Arthritis Rheum 2001; 44: 2065-71. doi: 10.1002/15290131(200109)44:9<2065::AID-ART356>3.0.CO;2-Z

8) Woo J, Lau E, Lee P, Kwok T, Lau WC, Chan C, et al. Impact of osteoarthritis on quality of life in a Hong Kong Chinese population. J Rheumatol 2004; 31: 2433-8. PMid: 15570647

9) Sinusas K. Osteoarthritis: diagnosis and treat $\neg$ ment. Am Fam Physician 2012; 85: 49-56. PMid: 22230308

10) Cheng OT, Souzdalnitski D, Vrooman B, Cheng J. Evidence-Based knee injections for the man $\neg$ agement of arthritis. Pain Med 2012; 13: 740-53. doi: 10.1111/j.1526-4637.2012.01394.x, PMid: 22621287, PMCid: PMC3376243

11) Frizziero A, Giannotti E, Ferraro C, Masiero S. Platelet rich plasma intra-articular injections: a new therapeutic strategy for the treatment of knee osteoarthritis in sport rehabilitation. A systematic review. Sport Sci Health 2012; 8: 15-22. doi: 10.1007/s11332-012-0126-5

12) Petrella RJ. Hyaluronic acid for the treatment of knee osteoarthritis: long-term outcomes from a naturalistic primary care experience. Am J Phys Med Rehabil 2005; 84: 278-83. doi: 10.1097/01.PHM.0000156899.18885.06, PMid: 15785261

13) Rodriguez-Merchan EC. Intraarticular injections of platelet-rich plasma (PRP) in the management of knee osteoarthritis. Arch Bone Jt Surg 2013; 1: 5-8. PMid: 25207275, PMCid: PMC4151401

14) Liberati A, Altman DG, Tetzlaff J, Mulrow C, Gøtzsche PC, Ioannidis JP, et al. The PRISMA Statement for Reporting Systematic Reviews and Meta-Analyses of Studies That Evaluate Health Care Interventions:Explanation and Elaboration. PLoS Medicine 2009; 6: e1000100. doi: 10.1136/bmj.d5928, PMid: 22008217, PMCid: PMC3196245

15) McConnell S, Kolopack P, Davis AM. The Western Ontario and McMaster Universities Osteoarthritis Index (WOMAC): A review of its utility and measurement properties. Arthritis Rheum 2001; 45: 453-61. doi: 10.1002/1529-0131(200110)45:5<453::AID-ART365>3.0.CO;2-W

16) Higgins JP, Altman DG, Gøtzsche PC, Jüni P, Moher D, Oxman AD, et al. The Cochrane Collaboration's tool for assessing risk of bias in randomised trials. BMJ 2011; 343: d5928.

17) Jadad AR, Moore RA, Carroll D, Jenkinson C, Reynolds DJ, Gavaghan DJ, et al. Assessing the quality of reports of randomized clinical trials: is blinding necessary? Control Clin Trials 1996; 17: 1-12. doi: 10.1016/0197-2456(95)00134-4 
18) Sánchez M, Anitua E, Azofra J, Aguirre JJ, Andia I. Intra-articular injection of an autologous preparation rich in growth factors for the treatment of knee OA: a retrospective cohort study. Clin Exp Rheumatol 2008; 26: 910-3. PMid: 19032827

19) Cerza F, Carnì S, Carcangiu A, Di Vavo I, Schiavilla V, Pecora A, et al. Comparison Between Hyaluronic Acid and Platelet-Rich Plasma, Intra-articular Infiltration in the Treatment of Gonarthrosis. Am J Sports Med 2012; 40: 2822-7. doi: 10.1177/0363546512461902, PMid: 23104611

20) Raeissadat SA, Rayegani SM, Hassanabadi H, Fathi M, Ghorbani E, Babaee M, et al. Knee Osteoarthritis Injection Choices: Platelet- Rich Plasma (PRP) Versus Hyaluronic Acid (A one-year randomized clinical trial). Clin Med Insights Arthritis Musculoskelet Disord 2015; 8: 1-8. PMid: 25624776, PMCid: PMC4287055

21) Sánchez M, Fiz N, Azofra J, Usabiaga J, Aduriz Recalde E, Garcia Gutierrez A, et al. A Randomized Clinical Trial Evaluating Plasma Rich in Growth Factors (PRGF-Endoret) Versus Hyaluronic Acid in the Short-Term Treatment of Symptomatic Knee Osteoarthritis. Arthroscopy 2012; 28: 1070-8. doi: 10.1016/j.arthro.2012.05.011, PMid: 22840987

22) Spaková T, Rosocha J, Lacko M, Harvanová D, Gharaibeh A. Treatment of Knee Joint Osteoarthritis with Autologous Platelet-Rich Plasma in Comparison with Hyaluronic Acid. Am J Phys Med Rehabil 2012; 91 : 411-7. doi: 10.1097/PHM.0b013e3182aab72, PMid: 22513879

23) Vaquerizo V, Plasencia MÁ, Arribas I, Seijas R, Padilla S, Orive G, et al. Comparison of Intra-Articular Injections of Plasma Rich in Growth Factors (PRGF-Endoret) Versus Durolane Hyaluronic Acid in the Treatment of Patients With Symptomatic Osteoarthritis: A Randomized Controlled Trial. Arthroscopy 2013; 29: 1635-43. doi: 10.1016/j.arthro.2013.07.264, PMid: 24075613

24) Khoshbin A, Leroux T, Wasserstein D, Marks P, Theodoropoulos J, Ogilvie-Harris D, et al. The efficacy of platelet-rich plasma in the treatment of symptomatic knee osteoarthritis: a systematic review with quantitative synthesis. Arthroscopy 2013; 29: 2037-48. doi: 10.1016/j.arthro.2013.09.006, PMid: 24286802

25) Meheux CJ, McCulloch PC, Lintner DM, Varner KE, Harris JD. Efficacy of Intra-articular Platelet-Rich Plasma Injections in Knee Osteoarthritis: A Systematic Review. Arthroscopy 2015; S0749-8063: 00659-3.

26) Chang KV, Hung CY, Aliwarga F, Wang TG, Han DS, Chen WS. Comparative effectiveness of plateletrich plasma injections for treating knee joint cartilage degenerative pathology: a systematic review and meta-analysis. Arch Phys Med Rehabil 2014; 95: 562-75. doi: 10.1016/j.apmr.2013.11.006, PMid: 24291594

27) Gobbi A, Karnatzikos G, Mahajan V, Malchira S. lateletrich plasma treatment in symptomatic patients with knee osteoarthritis: preliminary results in a group of active patients. Sports Health 2012; 4: 162-72. doi: 10.1177/1941738111431801, PMid: 23016084, PMCid: PMC3435904

28) Kon E, Mandelbaum B, Buda R, Filardo G, Delcogliano M, Timoncini A, et al. Platelet intra-articular injection versus hyaluronic acid viscosupplementation as treatments for cartilage pathology: from early degenerations to osteoarthritis. Arthroscopy 2011; 27: 1490-501. doi: 10.1016/j.arthro.2011.05.011, PMid: 21831567

29) Martin P, D'Souza D, Martin J, Grose R, Cooper L, Maki R, et al. Wound healing in the PU.1 null mouse-tissue repair is not dependent on inflammatory cells. Curr Biol 2003; 13: 1122-8. doi: 10.1016/S09609822(03)00396-8

30) Filardo G, Di Matteo B, Di Martino A, Merli ML, Cenacchi A, Fornasari P, et al. Platelet-Rich Plasma Intra-articular Knee Injections Show No Superiority Versus Viscosupplementation: A Randomized Controlled Trial. Am J Sports Med 2015; 43: 1575-82. doi: 10.1177/0363546515582027, PMid: 25952818

31) Weinstein JN, Tosteson TD, Lurie JD, Tosteson AN, Hanscom B, Skinner JS, al e. Surgical vs nonoperative treatment for lumbar disk herniationd The Spine Patient Outcomes Research Trial (SPORT): A randomized trial. JAMA 2006; 269: 2441-50. doi: 10.1001/jama.296.20.2441, PMid: 17119140, PMCid: PMC2553805 